\title{
Reflexiones sobre el movimiento Me Too y su filosofía
}

\author{
Jean-Claude Milner
}

Resumen

En octubre de 2017, The New York Times y The New Yorker publicaron decenas de acusaciones de abuso sexual contra el productor cinematográfico y ejecutivo estadounidense Harvey Weinstein por acoso, abuso sexual e incluso violaciones. Fue el inicio del movimiento «Me Too», conocido también por su hashtag «\#MeToo», viralizado a través de redes sociales por más de medio millón de personas, entre ellas muchas celebridades. El 11 de marzo de 2020 Weinstein fue sentenciado a 23 años de prisión. Harvey Weinstein se había hecho famoso en la década del 80 cuando junto a su hermano Bob fundaron la legendaria compañía Miramax. Como productor, Weinstein fue el artífice de grandes éxitos, como Shakespeare in Love (1998), Gangs of New York (2002), Reservoir Dogs (1992), Pulp Fiction (1994), Smoke (1995), El paciente inglés (1996) -por la que obtuvo su primer Óscar de la Academia-, Scream (1996), Inglourious Basterds (2009), El discurso del rey (2010), y The Artist (2011), entre muchas otros. La revelación de las escandalosas inconductas sexuales de Wainstein, que motivó su expulsión de la Academia de Artes y Ciencias Cinematográficas, abrió un debate sobre el séptimo arte, la lógica del mercado y el tratamiento de los cuerpos en el capitalismo. Este artículo de Jean-Claude Milner, constituye seguramente la reflexión filosófico-analítica más profunda sobre el tema. Etica y Cine Journal lo publica por primera vez en español con la cuidada traducción y notas de Valentín Huarte, como un imprescindible aporte a una discusión que debe permanecer abierta bajo cualquier circunstancia.

Mariana Gómez, Irene Cambra Badii y Juan Jorge Michel Fariña Editores

Palabras clave: Metoo | Milner| psicoanálisis | Weinstein

Reflections on the Me Too movement and its philosophy

\begin{abstract}
In October 2017, The New York Times and The New Yorker published dozens of sexual abuse allegations against American film producer and executive Harvey Weinstein for harassment, sexual abuse, and even harm. It was the beginning of the "Me too" movement, also known by its hashtag "\#MeToo", viralized through social networks by more than half a million people, including many celebrities. On March 11, 2020 Weinstein was sentenced to 23 years in prison. Harvey Weinstein had become famous in the 1980s when he founded the legendary company Miramax with his brother Bob. As a producer, Weinstein was the architect of great successes, such as Shakespeare in Love (1998), Gangs of New York (2002), Reservoir Dogs (1992), Pulp Fiction (1994), Smoke (1995), The English Patient (1996) -for which he obtained his first Academy Oscar-, Scream (1996), Inglourious Basterds (2009), The King's Speech (2010), and The Artist (2011), among many others. The revelation of Wainstein's scandalous sexual misconduct, which motivated his expulsion from the Academy of Motion Picture Arts and Sciences, opened a debate on the seventh art, the logic of the market and the treatment of bodies in capitalism. This article by Jean-Claude Milner determines the deepest philosophical-analytical reflection on the subject. Etica y Cine Journal publishes it for the first time in Spanish with the careful translation and notes of Valentín Huarte, as an essential contribution to a discussion that must remain open under any circumstances.
\end{abstract}

Keywords: Metoo | Milner | Psychoanalysis | Weinstein

Publicado originalmente en inglés en PROBLEMI INTERNATIONAL, vol. 3, no. 3, 2019 [https://problemi.si/issues/p2019-3/04problemi_international_2019_3_milner.pdf]

Traducción y notas de Valentín Huarte ${ }^{1}$

La importancia del caso Harvey Weinstein excede por mucho al brote de emoción que provocó. Concierne en verdad a la representación general de las relaciones sexuales. Para decirlo rápidamente, el caso dio origen a un cambio de paradigma. El movimiento Me Too es tanto una consecuencia como un síntoma de ese cambio.

\section{El origen y la estructura del movimiento Me Too}

Ha habido muchos escándalos sexuales en la historia de Hollywood. Pero han sido considerados como transgresiones de un estándar de conducta generalmente aceptado. De manera indirecta, confirmaban que la violación no era la regla sino una excepción muy frecuente. En el caso Weinstein, por el contrario, el escándalo no se produjo por el hecho de que la regla fuera infringida, sino que la regla misma se invirtió. La violación era la regla, no la excepción. Además, la situación no fue considerada como una singularidad de la industria del cine; se seguía de la misma estructura del acto sexual. Reveló la verdadera naturaleza de lo que sucede entre los seres humanos cada vez que se comprometen en la actividad sexual: no solo en Hollywood, no solo en Estados Uni- 
dos, sino en cualquier lugar. La consigna "Me Too" es en sí misma significativa: la palabra too [también] implica un mecanismo de adición indefinida. Significa que cada ser humano puede haber sido en el pasado, o podría convertirse en el futuro, en una víctima de la misma regla sexual que permitió a Harvey Weinstein y a otros actuar como lo hicieron.

A pesar de que el caso Weinstein y el movimiento $\mathrm{Me}$ Too tienen una significación universal, no es sorprendente que tomen su lugar en Estados Unidos. La historia de EEUU comenzó con una lucha contra lo que los inmigrantes Europeos consideraban como salvajismo. La naturaleza debía ser domesticada; los nativos fueron rápidamente identificados como salvajes y exterminados en tanto tales. Sin embargo, cuando esas tareas habían sido completadas, se mostró que todavía en el S. XX permanecía un área oscura donde el salvajismo prevalecía: la vida sexual. Si la sociedad estadounidense quería seguir siendo fiel a sus principios fundantes, necesitaba civilizar el último resto de animalidad brutal. La completa igualdad entre hombres y mujeres, la corrección política de las prácticas cotidianas, la prohibición de las microagresiones: un programa tal parecía tan necesario como suficiente para reducir el salvajismo sexual.

Europa Occidental fue de alguna manera lenta en el relevo. Por mucho tiempo, estaba convencida de que ya había perfeccionado un modelo definitivo de civilización, que había comenzado con el Humanismo del Quattrocento y alcanzado su pico a comienzos del siglo veinte. Es cierto que las dos guerras mundiales destruyeron muchos de sus logros. Pero nada esencial debía ser agregado al modelo mismo, especialmente en cuestiones sexuales. La tarea era simplemente restaurar lo que se había perdido. La sociedad estadounidense, por el contrario, concebía la civilización como un work in progress. El modelo europeo era solo un punto de partida, especialmente en cuestiones sexuales. Por ese motivo, la reforma sexual se convirtió en una de las principales preocupaciones de la reflexión práctica y teórica en Estados Unidos. De esta manera, la sociedad seguía siendo fiel a aquello a lo que había adherido desde los comienzos de su historia: el salvajismo debe ser reducido no solo a nivel colectivo, sino también entre individuos e incluso en la mente de cada individuo. En este dominio, los intelectuales de Estados Unidos tomaron la iniciativa en los años 1960; la cultura europea tuvo que seguirlos.

Aun así, el caso Weinstein mostró también que la corrección política y el destierro de las microagresiones había fallado. El activismo liberal y feminista no había considerado adecuadamente la realidad continuada de las macroagresiones. De hecho, lejos de ser una continuación del feminismo, el Me Too implica una dura crítica a sus dogmas y un desprecio velado hacia sus representantes. El caso Weinstein, en particular, pareció demostrar que la ideología de la corrección política había sido solo eso: una ideología, que se mostró radicalmente inefectiva contra la realidad del salvajismo sexual. La insistencia sobre las microagresiones había llevado a descuidar las macroagresiones. La cuestión que debía plantearse no concernía a los efectos colaterales de la vida sexual o a su estructura de superficie; más bien, implicaba la estructura profunda de la vida sexual y el núcleo de su estructura, a saber, el coito. A pesar de que esas discusiones se habían desarrollado en la literatura feminista, habían sido confinadas a los círculos académicos. De acuerdo con el Me Too, el campo de batalla decisivo ya no era el campus; era más bien la opinión pública. La utilidad de los artículos ingeniosos y los libros brillantes pertenecía al pasado. Los medios masivos y las redes sociales eran más importantes. La cuestión del coito debía ser planteada sin rodeos; para hacer eso, celebridades menores sin educación eran preferibles a los íconos de los Women's Studies.

En verdad, el movimiento Me Too pareció oscilar casi inmediatamente entre dos concepciones. Al principio, el centro del escándalo fue la violencia sexual en sí misma. Ciertamente, Harvey Weinstein tenía el poder para promover o destruir las carreras de las mujeres que usaba, pero este hecho era la condición auxiliar que le permitía ejercer una coacción sin nunca temer ser capturado o denunciado. No era el factor definitivo. En un segundo período, parecía que el hecho central era, por el contrario, la manera en la cual Harvey Weinstein había hecho un uso incorrecto de la posición profesional que ocupaba; mientras que su casi ilimitado poder se estimaba aceptable, siempre y cuando beneficiara a la industria del cine, se volvió vergonzoso una vez que se convirtió en un medio para satisfacer apetitos sexuales personales. $\mathrm{La}$ dimensión sexual se añadía, por supuesto, a la gravedad del crimen; pero el escándalo real recaía sobre el quebrantamiento de una regla profesional.

En efecto, hay dos caras del movimiento. Una puede ser llamada el movimiento Me Too sexual; la otra puede ser llamada el movimiento Me Too "profesionalista". Es la primera la que tuvo un eco casi universal en el mundo, así como seguidores en países en los cuales las estructuras profesionales son completamente diferentes de las que prevalecen en EEUU. Sin embargo, el segundo 
movimiento parece haber ganado mayor prominencia recientemente en EEUU, dejando atrás, por lo tanto, la universalidad de sus comienzos. ${ }^{2}$

Precisamente en virtud de su vocación universal, el movimiento $\mathrm{Me}$ Too sexual merece atención especial. Centraré mi análisis en sus implicaciones intelectuales. Sea lo que sea que haya sucedido después, hay una novedad que es innegable: con una intensidad sin precedentes, el movimiento planteó pública y ampliamente la cuestión del coito.

\section{Datos históricos sobre las concepciones del acto sexual}

Históricamente, el coito fue concebido de dos maneras diferentes: sea como la fusión de dos cuerpos en uno o sea como el uso de un cuerpo por otro. La principal diferencia entre los dos modelos reside en el estatus de unidad y dualidad. La fusión requiere que dos cuerpos se conviertan en uno, aunque más no sea por un instante; el uso permite que los dos cuerpos permanezcan, hasta el final, separados y distintos. ${ }^{3}$ Un ejemplo común de fusión es la incorporación de comida; una vez que han sido digeridos, el pan o el agua se convierten en un elemento en el cuerpo de quien comió o bebió. El Dos se convierte en Uno. Por otro lado, el usuario de una herramienta y la herramienta misma están separados de la misma forma tanto al comienzo como al final del proceso. La Dualidad es irreductible.

Platón adoptó el paradigma de la fusión pero tuvo que concebir una estratagema para lidiar con esta, dado que estaba convencido de que la fusión de dos cuerpos era imposible; por consiguiente, sustituyó almas por cuerpos. La fusión de las almas era supuestamente capaz de superar los defectos del acto físico. El poeta y filósofo latino Lucrecio también estaba convencido de la imposibilidad de la fusión sexual; pero como epicúreo, rechazó la estrategia de la substitución de Platón. En el cuarto libro de De rerum natura, escrito en el primer siglo antes de cristo, expone la doctrina más oscura posible del coito. Su meta imaginaria es la fusión, pero esta meta no puede ser alcanzada; los miembros de la pareja sexual gimen y los esfuerzos físicos dan cuenta de que están perdidos en la persecución de una ilusión. Dado que el ejemplo más obvio de una fusión sexual es la incorporación de comida, cada compañero busca morder la carne del otro o beber sus fluidos; pero inmediatamente entienden que estas tácticas nunca tienen éxito. Lucrecio concluye diciendo que no hay tal cosa como el placer sexual; incluso entre los cuerpos más hermosos y enamorados, el coito resulta en el sufrimiento y la decepción. Es la búsqueda infructuosa de lo imposible, que no puede evitar el constante riesgo de la brutalidad, incluso del salvajismo.

El poema de Lucrecio debe haber impactado a sus lectores contemporáneos. Eso explicaría por qué estuvo perdido hasta el Renacimiento. Incluso luego de que el texto fue redescubierto, su doctrina del coito fue a menudo pasada por alto. Kant es una excepción mayor. A pesar de que no cita el nombre de Lucrecio, adopta su perspectiva. Además, vuelve explícito el axioma subyacente del poeta latino: en 1798, Kant afirma abiertamente: "el goce [enjoyment] carnal es canibalesco en principio (aun si no siempre lo es de manera efectiva)" (Kant, 1996, p. 127). ${ }^{4}$

Tanto en Lucrecio como en Kant, la relación es simétrica. Cada miembro de la pareja es tan brutal y bestial como el otro. No hay diferencia, a este respecto, entre hombre y mujer. Mientras que los dos enfoques comparten esta similitud esencial, difieren, sin embargo, en un asunto crucial. Lucrecio adhiere a un único paradigma, a saber la fusión de dos cuerpos en uno: no hay superación de esta imposibilidad; no hay remedio para el salvajismo radical y la eventual insatisfacción del coito. Kant, por el contrario, combina los dos paradigmas, el de la fusión y el del uso; además, el último es concebido como una solución a la tendencia canibalesca del primero.

De acuerdo con Kant (1873), en el acto sexual el hombre usa algunas partes del cuerpo de la mujer y la mujer usa algunas partes del cuerpo del hombre ${ }^{5} \mathrm{~A}$ pesar de que Kant no considera las relaciones homosexuales, su análisis podría fácilmente extenderse a estas. El canibalismo se evita porque la o el usuario no busca la destrucción de la herramienta que usa. Sin embargo, hay un precio a pagar. Cada miembro de la pareja niega la humanidad de su propio cuerpo. Por dos razones: a) se trata a sí mismo y al otro como una simple cosa; b) se rebaja a sí mismo y al otro a la posición de usuario de otro ser humano.

La solución a esta dificultad se encuentra en la forma del contrato. Cada miembro de la pareja brinda su consentimiento explícito; ambos lo hacen libre y simultáneamente. Cada miembro de la pareja actúa como un sujeto libre en el mismo momento en el cual una parte de su cuerpo es puesta en uso; cada uno de ellos trata al otro como un sujeto libre en el mismo momento en el que usa el cuerpo del otro. Los dos acuerdan en ser tratados simultánea y simétricamente como cosas pasivas y como 
sujetos morales libres. En la medida en que ninguno de los dos olvide los términos del contrato, el salvajismo radical del coito es exitosamente superado.

Muchos comentadores han considerado estas reflexiones como irremediablemente obsoletas o incluso ridículas. Pero en la actualidad muchos países han revivido el enfoque kantiano. La única modificación importante concierne al matrimonio. Kant sostenía que el consentimiento libre debía ser dado de una vez y para siempre; por consiguiente, argumentó que la única institución que lo materializa adecuadamente es el matrimonio monógamo. En la actualidad, el matrimonio no se estima necesario ni suficiente; el consentimiento libre debe ser dado explícitamente por ambos miembros de la pareja -estén casados o no- antes de cada acción singular considerada sexual, sea el coito, un simple beso, o incluso una mirada. Los países escandinavos, en particular, tienen mucha confianza en este tipo de regulación social. En ausencia de un documento firmado por ambas partes, todo tipo de acción sexual debe ser considerada como intento de violación.

\section{La crítica de Marx a la forma del contrato en general}

Esta confianza en la forma del contrato no puede ser considerada como autoevidente. Marx (1982), por ejemplo, formuló objeciones radicales en contra de ella. El primer libro de El capital se aboca a un minucioso análisis del contrato de trabajo. Intenta mostrar que tal contrato es simétrico solo en apariencia; en realidad, se basa una asimetría irreductible. El trabajador puede aparentar ser libre de vender su tiempo de trabajo de la misma manera en que el empleador es libre de contratar un trabajador. Sin embargo, hay una diferencia: el trabajador debe vender su fuerza de trabajo para sobrevivir, mientras que el empleador piensa sólo en función de la ganancia. La supervivencia y la ganancia no pueden ser consideradas como simétricas. A pesar de que Marx enfatizó la especificidad del contrato de trabajo -es decir, la plusvalía- su enfoque excede por mucho a la especificidad del contrato de trabajo. ${ }^{6}$ Plantea una cuestión general: ¿es alguna vez simétrico un contrato entre seres humanos?

De manera curiosa, Kant mismo brinda un ejemplo que valida las dudas de Marx. Luego de haber apuntado hacia la naturaleza canibalesca del intercambio sexual, agrega: "Ya sea que algo se consuma con boca y dientes, o que la mujer sea consumida por el embarazo y el parto acaso fatal que resulta de este, o el hombre por el agotamiento de su capacidad sexual en función de las frecuentes demandas de la mujer, la diferencia se encuentra simplemente en la manera de gozar [enjoyment] (Kant, 1996, p. 127). ${ }^{7}$ Obviamente, se considera que el hombre y la mujer se encuentran "igualmente" en riesgo. Nadie negaría la pertinencia del juicio de Kant sobre los peligros mortales del embarazo y del parto. Pero el "agotamiento de la capacidad sexual del hombre en función de las frecuentes demandas de la mujer" no da lugar a la misma certeza. El lector moderno difícilmente pueda disimular una sonrisa; pero es interesante notar que en el siglo diecinueve, las reacciones deben haber sido similares. Por ejemplo, cuando la Metafísica de las costumbres fue parcialmente publicada en inglés bajo el título "The Philosophy of Law", el traductor convenientemente suprimió esas líneas (Kant, 1887). No solo son ridículas; también revelan la imposibilidad de igualar los peligros a los que hombres y mujeres se someten. Exactamente como con los trabajadores y los empleados, no hay medida común. Lo que está en juego para las mujeres es una cuestión de vida o muerte (esto valía especialmente en 1789 , pero sigue siendo verdadero en la actualidad); lo que está en juego para los hombres es, cuanto mucho, una cuestión de confort y longevidad.

Kant se apoyaba sobre la forma del contrato porque le permitía regular el modelo del uso. Marx criticó la forma del contrato, pero también analizó la relación de uso en sí misma. Su concepción del valor de uso debe ser tenida en cuenta. ${ }^{8}$ Para hacer uso de un cuchillo, el usuario debe dominar [master] al cuchillo; esto vale para todo tipo de herramientas. También vale para el uso del cuerpo de un ser humano por otro ser humano. Mientras hacen uso de algo o de alguien, los usuarios dominan [master] lo que usan. Pero entonces la relación relevante no es otra que la dominación [domination]. ${ }^{9}$ Siempre que el uso está involucrado, está en juego la dominación. El contrato de trabajo es un caso ilustrativo. Es desigual en dos sentidos distintos: a) es desigual porque es un contrato, $\mathrm{y}$ todos los contratos son asimétricos; b) también es desigual porque involucra el uso, y el uso implica la dominación. Entre un usuario y una herramienta inanimada, la dominación no implica necesariamente dominación social del usuario sobre la herramienta; no debe expresarse necesariamente en términos de poder. Pero entre dos seres humanos, la dominación toma inmediatamente un carácter social, oponiendo un ser socialmente (y a veces físicamente) más fuerte a un ser socialmente más débil. 
Desde este punto de vista, la solución de Kant se vuelve irrelevante, porque no hay tal cosa como una dominación recíproca. Nadie puede ser a la vez fuerte y débil desde el mismo punto de vista y en el mismo momento. Por supuesto, puede haber períodos sucesivos en los que la dominación cambia su orientación. El antiguo amo puede convertirse en el esclavo y el antiguo esclavo puede convertirse en el amo; pero es imposible concebir una combinación simultánea de roles opuestos. Análogamente, un individuo puede dominar a otro en un sentido, mientras es dominado en otro sentido. Pero en la concepción kantiana, los roles opuestos deben ser definidos exactamente en los mismos términos y en el mismo momento. Ese requisito es crucial; y, de acuerdo con el análisis de Marx, es imposible satisfacerlo.

Consecuentemente, el enfoque de Kant se encuentra debilitado en dos puntos. En primer lugar, la creencia de Kant en la naturaleza simétrica de los contratos es rechazada como una ilusión. Ningún contrato es simétrico, porque lo que está en juego para una parte y lo que está en juego para la otra siempre difiere de manera radical; pero en un contexto social (y el contrato entre seres humanos es inmediatamente social), la diferencia implica la desigualdad. En todos los contratos, uno de los miembros de la pareja pierde (o gana) más que el otro. En segundo lugar, la relación de uso en sí misma implica un cierto tipo de dominación. Entre dos seres humanos, la dominación es la dominación del débil por el fuerte.

Por supuesto, el enfoque de Marx no menciona el acto sexual, pero, a pesar de haber sido concebido como una crítica de la economía política, su relevancia es mucho más amplia. Muchas discusiones del acto sexual se basan de hecho en demandas fácilmente traducibles en términos marxianos. Las protestas que siguieron al caso Weinstein son un ejemplo excelente. Es cierto que la teoría de Marx no parece haber sido una fuente de inspiración para quienes lideran el movimiento Me Too, pero eso no afecta la analogía lógica de los argumentos.

\section{El caso Weinstein y la teoría del contrato}

No debe subestimarse la situación que se impuso a fines del siglo veinte. Luego de una larga lucha, la concepción liberal de la sociedad alcanzó una victoria casi completa. En las sociedades occidentales, se admitía generalmente que el consentimiento mutuo ofrecía la mejor base posible para las relaciones humanas, no sólo desde un punto de vista ético, sino también en términos de éxito material. Se pensaba que el contrato, más que la ley, era la expresión más adecuada del consentimiento mutuo. Incluso entre intelectuales, donde las objeciones marxianas fueron tomadas en cuenta por mucho tiempo, el enfoque liberal empezó a ser aceptado como un punto de partida indisputable. Especialmente en EEUU, la primacía del consentimiento mutuo parecía encontrarse fuera de toda duda, particularmente en cuestiones sexuales. Todo tipo de asimetría entre seres humanos fuertes y débiles podía ser resuelta de esta manera.

El caso Weinstein explotó estas creencias. En el mismo país en donde el consentimiento mutuo definía la regla última, su efectividad social parecía casi nula en lo que concernía a las relaciones sexuales. Esto es así porque estas relaciones están basadas siempre en la desigualdad. Esa estructura es tan general que el consentimiento mutuo pierde todo significado. Ciertamente, muchas de las víctimas de Weinstein no habían dado su consentimiento; pero algunas de ellas sí lo habían hecho. Cuando su testimonio fue objetado, explicaron que su supuesta aprobación se siguió de los riesgos que corrían si se negaban. En términos más generales, incluso si la parte más débil -él o ella- da su consentimiento, esa aprobación no compensa su debilidad relativa. En el contrato de trabajo, puede parecer que los trabajadores dan su consentimiento libre; pero su debilidad estructural sigue siendo el factor determinante para su aprobación. Lo mismo vale para el así llamado contrato sexual.

Es legítimo sacar algunas conclusiones generales sobre el caso Weinstein. El acto sexual constituye la base de existencia material de cualquier tipo de sociedad humana. Si es esencialmente desigual, entonces esa desigualdad podría extenderse a cualquier tipo de relación en una sociedad dada. Puede desarrollarse un análisis general de la desigualdad social; será análogo al análisis de Marx, excepto por el hecho de que encontrará su punto de partida en la relación sexual en lugar de hacerlo en el contrato de trabajo. Este tipo de análisis no comenzó con el caso Weinstein. Durante los años 1960, se extendió ampliamente en el campo intelectual; pero en ese período la teoría marxista era bien conocida. Su enfoque podía ser aplicado fácilmente al análisis de las relaciones sexuales. Un enfoque de estas características se concebía como una extensión del marxismo.

Con el caso Weinstein nos encontramos en la situación inversa: la reflexión comienza con la desigualdad sexual y el análisis social no es más que una extensión de esta. Además, la reflexión sobre las relaciones sexuales no está confinada a los círculos intelectuales; por el 
contrario, comienza como una reacción masiva de la denominada mayoría silenciosa, que de repente deja de callar. Consecuentemente, sería imprudente suponer que las analogías con la doctrina de Marx son de común conocimiento entre los seguidores del movimiento $\mathrm{Me}$ Too. Tampoco es siempre explícito el rechazo del modelo contractual. En cambio, la referencia al patriarcado se considera suficiente para caracterizar el tipo de sociedad que permitió a Weinstein y a otros actuar como lo hicieron.

El Me Too es de hecho un fenómeno de masas. Mientras que la creación de un campo académico sobre Women's Studies [Estudios de la mujer] puede ser considerada como una importante victoria del feminismo, las consecuencias del caso Weinstein exceden los límites de lo que podría denominarse la burguesía intelectual. Algunas figuras del feminismo temprano son incluso bastante duras con el Me Too; el movimiento Me Too, por su parte, es bastante indiferente a sus críticas y generalmente no busca justificación en los trabajos teóricos de feministas anteriores. Pero eso no significa que no haya proposiciones conceptuales en el movimiento. Por el contrario, aun si no son explícitas, estas proposiciones pueden ser especificadas. Pueden combinarse para formar una doctrina, o más bien una filosofía.

\section{La filosofía del movimiento Me Too sexual}

Las demandas más importantes conciernen a la oposición entre lo débil y lo fuerte. Antes que nada, la razón por la cual la forma del contrato es inefectiva radica en el hecho de que no hay contrato justo en donde una parte es más débil que la otra. Tal es el caso de las relaciones sexuales. En segundo lugar, la debilidad y la fuerza no son cualidades descriptivas; son más bien estructurales. Puede pasar que la parte estructuralmente débil parezca, desde un punto de vista descriptivo, más fuerte que la parte estructuralmente fuerte. Eso no afecta la efectividad de la estructura. En tercer lugar, en las relaciones sexuales, la mujer es estructuralmente más débil que el hombre. Es irrelevante comprobar si una mujer particular es más fuerte, más influyente, rica o incluso físicamente más fuerte que un hombre. Estas son características descriptivas; no tienen ninguna consecuencia cuando son comparadas con el hecho estructural de que la mujer como tal es la parte débil.

Esto derriba las representaciones usuales. Por mucho tiempo, se pensó en la debilidad femenina en términos descriptivos o en términos machistas. El programa feminista negaba este hecho o buscaba compensarlo con logros variados, en términos de competencia intelectual, poder social, éxito profesional, y cosas por el estilo. El machismo ridiculizaba repetidamente estos logros volviendo hacia el nivel físico más simple. Desde el movimiento Me Too, el argumento machista ha sido revertido; en lugar de justificar una inferioridad general de las mujeres, la debilidad estructural de las mujeres legitima los derechos específicos de las mujeres. Obviamente, la importancia de los logros sociales o intelectuales se mantiene; pero no tiene ninguna relevancia para la estructura del coito. Incluso en las sociedades occidentales, donde las mujeres han hecho un progreso decisivo en términos de poder social, cada mujer singular es impotente cuando la amenaza es el riesgo de violación. No hay necesidad de investigar la cuenta bancaria de una mujer ni de medir su fuerza física para probar que este riesgo existe. Es una cuestión de estructura; y esa estructura depende de la relación sexual en sí misma, tal como se muestra en el coito. Donde el riesgo específico existe, la protección específica es necesaria.

Consecuentemente, cada acto sexual entre un hombre y una mujer es una violación potencial, independientemente de si ella inicialmente dio su consentimiento, tomó la iniciativa o experimentó placer. Podría pasar incluso que una mujer sienta retrospectivamente que fue sometida a algún tipo de violencia física o psicológica; a pesar de que no lo sintió durante el acto, su reclamo tardío está justificado. Hasta ahora, una diferencia de esencia separaba el coito legítimo de la violación; desde el caso Weinstein, de acuerdo con la filosofía del Me Too, la diferencia es simplemente de grado. El criterio reside en la sensibilidad de la mujer, no en el consentimiento. $\mathrm{Si}$ antes, durante, o luego (incluso mucho después) del coito, ella siente la más mínima huella de violencia, ha sido violada. Dado que la violación es un crimen contra la humanidad, debería ser imprescriptible.

De acuerdo con esta doctrina, es irrelevante argumentar que un sentimiento es de naturaleza subjetiva; es irrelevante argumentar que los recuerdos pueden engañar. Lo que es relevante es que la mujer, aquí y ahora, siente que ha experimentado su propia debilidad. Ese sentimiento no es subjetivo per se; refleja la estructura objetiva que gobierna el coito. Después de todo, muchos lingüistas sostienen que el sentimiento intuitivo que experimentan los hablantes en relación con su lengua materna es la evidencia más fiable de esa lengua ¿Por qué? Porque refleja directamente la estructura objetiva de la 
gramática. Lo mismo vale para los sentimientos de la mujer acerca del coito en el cual ella participó.

Una vez más, el enfoque de Marx brinda una analogía fructífera. De acuerdo con su doctrina, puede pasar, en algunos casos excepcionales, que el contrato de trabajo sea equitativo. Esto no reduce la desigualdad que caracteriza la relación capitalista entre el empleador y el trabajador. Incluso cuando un contrato de trabajo pasa todas las pruebas legales y económicas, su estructura profunda no es nada más que fraude. Entre un empleador honesto y un criminal, la diferencia es de grado, no de esencia. El empleador-ladrón revela la verdadera naturaleza del empleo legítimo. Sin ninguna referencia explícita a $E l$ Capital, la filosofía del Me Too concibe de esta manera el vínculo entre el coito ordinario y la violación. La última revela la verdadera naturaleza del primero.

En el Preámbulo a la Declaración francesa de los derechos de 1789, la frase crucial es la siguiente: les hommes naissent et demeurent libres et égaux en droits, "los hombres nacen y permanecen libres e iguales en derechos". Tan pronto como fue publicada, algunas mujeres objetaron el carácter exclusivo del sustantivo hommes (hombres). Pero incluso si el sustantivo se entiende de manera inclusiva, en referencia tanto a hombres como a mujeres, el principio fundante de la Declaración no puede ser aprobado por la filosofía del Me Too. En su forma extrema, esa filosofía negaría que los hombres y las mujeres nacen iguales en términos de fuerza, mientras que también rechazaría la fórmula de Simone de Beauvoir: "No se nace mujer, se llega a serlo" (de Beauvoir, 2010, p. 283). ${ }^{10}$ Sea como sea, en cualquiera de sus versiones negaría que hombres y mujeres permanecen iguales. Esa conclusión negativa parecería volver a los estereotipos machistas más antiguos; de todas maneras, es necesario entenderla de una forma nueva: si los hombres y las mujeres fuesen tratados por la sociedad como seres perfectamente iguales en todos los sentidos, en tal mundo ideal se impondría todavía una desigualdad fundamental. Su base yace en la relación sexual y en su materialización central, a saber, el coito.

Dada esa desigualdad estructural y constante, la cuestión de los derechos debe ser reconsiderada. Es imposible conformarse con la noción abstracta de igualdad resumi$\mathrm{da}$ en el enunciado "los seres humanos nacen iguales en derechos". Una nueva noción de derechos debe ser definida: los derechos tienen por misión esencial proteger al débil contra el fuerte. Si la esencia de los derechos es la protección del débil, una consecuencia se sigue inmediatamente: sólo el más débil debe tener derechos reales. Dada la tesis "las mujeres son la parte estructuralmente débil en la relación sexual", la consecuencia implica que solo las mujeres tienen derechos en todas las cuestiones que involucran la relación sexual y especialmente el coito. En otras palabras, la noción de derechos humanos es una ilusión, dado que presupone un núcleo de derechos común a la parte débil y a la parte fuerte.

Esto es lo que sucede hoy en el terreno jurídico. Siempre que las relaciones sexuales estén en cuestión, no hay lugar para un juicio justo. Se considera impropio invocar la noción de "duda razonable". En cualquier caso, ninguna duda debería beneficiar a un hombre acusado de un abuso sexual de ningún tipo. En síntesis, la gravedad de la acusación debería bastar para validar la acusación en sí misma. En casos extremos, la identidad individual del culpable podría no ser establecida con certeza. Considerando la naturaleza de la monarquía, Saint-Just declaró, durante el juicio a Louis XVI: "Nadie puede reinar inocentemente”. La filosofía del Me Too implica de la misma manera que ningún hombre puede actuar inocentemente en el coito. En otras palabras, los hombres no tienen derechos en el dominio de las relaciones sexuales.

Hay un argumento que se usa con frecuencia para justificar la irrelevancia de la concepción clásica de los derechos. Por un largo período de tiempo, los hombres se beneficiaron de ventajas injustas, especialmente cuando las mujeres los acusaban de malas conductas, brutalidades o violaciones; dada tal tradición de injusticia y negación, es una cuestión de simple compensación que, en algunos casos, el balance deba ser revertido. En cualquier caso, la filosofía del Me Too va más lejos; sostiene que la única arma efectiva en contra de la inequidad es la inequidad misma, dado que invierte sistemáticamente la orientación de la inequidad anterior. Cuando los abogados de Harvey Weinstein objetan la manera en la cual su cliente será enjuiciado, tienen un punto, pero no toman en cuenta lo que está en juego, a saber, un cambio total de paradigma.

\section{Cuatro cuestiones sobre la filosofía del Me Too}

La filosofía del movimiento Me Too sexual merece ser considerada con cuidado. En otras palabras, merece ser criticada. Por más justificadas que estén las revueltas en el origen de este movimiento de protestas masivo, es legítimo cuestionar algunos aspectos de su racionalización ideológica.

La primera cuestión concierne al análisis del acto sexual. Puede indagarse en torno a la base material de 
la partición estructural entre partes débiles y fuertes. La única respuesta plausible tiene que ver con la penetración: la mujer es la parte débil en el coito porque su cuerpo es penetrado. En uno de sus últimos escritos, "Joyce le Symtpôme" (Lacan, 2001), ${ }^{11}$ Lacan propone una teoría del cuerpo. Delimita la relación expresada en la proposición "tener un", y define al ser humano como teniendo un cuerpo. Al mismo tiempo, rechaza la relevancia de la relación expresada por "ser un". Desde un punto de vista meramente lingüístico, es interesante notar que el verbo "tener" (como el verbo francés avoir) excluye la posibilidad de una identidad entre sujeto y objeto. A pesar de ser transitivo, "tener" no puede ser usado de manera reflexiva: "Yo me tengo a mí mismo" parece gramaticalmente extraño, en tanto "tener" significa "estar en posesión de", aunque "soy dueño de mí mismo" [I own myself] se ha vuelto bastante frecuente en la terminología psicológica. En francés, lo mismo vale para el imposible je m'ai [me tengo] o il s'a [él se tiene], en contraste con el inusual aunque posible je me possède [me contengo], il se possède [él se contiene]. Pero en la penetración ¿es todavía verdad que la mujer penetrada tiene su propio cuerpo?

Ciertamente, Lacan no menciona el acto sexual en "Joyce le Symptôme". Pero es legítimo aplicarle este modelo. Un paso decisivo lo da el texto al introducir la frase "tener un ser humano" [to have a human being]. Puisque l'homme a un corps, c'est par le corps qu'on l'a: "Porque el hombre tiene un cuerpo, es por medio del cuerpo que uno lo tiene a él" (Ibíd., p 568). ${ }^{12}$ Por supuesto que Lacan estaba al tanto de las dificultades que provoca el uso de la frase sustantiva "l'homme" [el hombre] y de su traducción al inglés man [hombre]. A pesar de que el artículo no las trata directamente, es obvio que bomme y man deben ser entendidos de manera inclusiva. ${ }^{13}$ Una paráfrasis posible podría ser: Alguien tiene a un ser humano, sea hombre o mujer, por medio del cuerpo que ese ser humano tiene.

Esa fórmula resume la doctrina última de Lacan sobre la dominación. Una consecuencia implícita se sigue: el ser humano -sea él o ella-que algún otro tiene no tiene más su cuerpo completamente. A pesar de que Lacan no usa la forma pasiva, es conveniente expresar la situación de un ser dominado como sigue: El ser humano es tenido por medio del cuerpo que él o ella tiene. El ejemplo que da Lacan es tomado de la historia del siglo veinte; obviamente, estaba pensando en los campos de concentración. Pero consideremos el coito: ¿ es absurdo sostener que la mujer penetrada es tenida por medio de la penetración del cuerpo que ella tiene? ¿Es absurdo considerar que, durante la penetración, ella no tiene su cuerpo de la misma manera que antes de la penetración? Un enfoque de este tipo podría fácilmente extenderse a las relaciones homosexuales, y el movimiento Me Too siempre se mostró preocupado por las violencias y abusos entre parejas sexuales del mismo género. En síntesis, la concepción de Lacan podría ser aceptada en la filosofía del Me Too.

Sin embargo, debería tenerse en cuenta una sutileza. Lacan no sostiene que un cuerpo está dominando a otro cuerpo; él dice que un ser humano domina a otro ser humano por medio del cuerpo de este último, o que un ser humano es dominado por otro ser humano por medio de su propio cuerpo. Dado que Lacan se rehúsa a considerar que el ser humano es su cuerpo, la dominación se produce entre seres humanos en lugar de entre cuerpos humanos. De todas maneras, la filosofía del $M e$ Too parece más bien inclinarse a aceptar la ecuación entre ser bumano = cuerpo bumano. En otras palabras, la concepción de Lacan de la relación sexual sigue siendo una relación entre seres humanos (por medio de los cuerpos que tienen); no es una relación entre cuerpos. Por el contrario, la concepción del coito del Me Too parece ser una relación entre dos cuerpos materiales, definida por su anatomía material, en lugar de una relación entre seres humanos.

El coito y la penetración conllevan dominación. La dominación conlleva la pérdida parcial o total por parte de la mujer dominada del cuerpo que ella tiene. Una vez más, el análisis podría ser modificado para incluir relaciones homosexuales. El movimiento Me Too sexual considera que las consecuencias de esta estructura son omnipresentes y afectan todas las relaciones sexuales que involucran a los hombres, sin importar cuán amables puedan ser. Pero en ese caso, la filosofía del movimiento Me Too sexual se retrotrae al decir de Freud: "La anatomía es destino" (Freud, 2001 [1912], p. 189). ${ }^{14}$ En otras palabras, ahí donde los Women Studies lograron separar el género de la anatomía, el Me Too vuelve a una forma de determinismo anatómico particularmente fuerte. Una vez más, rompe con las concepciones feministas anteriores.

En cualquier caso, debe plantearse una segunda cuestión ¿Es esta vuelta a la anatomía necesaria y suficiente para resolver los múltiples problemas que surgen en relación con la identidad sexual? ¿El movimiento $M e$ Too vuelve la noción de género completamente obsoleta? Dado que la cirugía (vaginoplastia o faloplastia) es la única manera que permite la penetración pasiva o activa 
$¿$ debe convertirse en el procedimiento privilegiado en relación con los deseos de las personas transgénero?

Un tercer interrogante concierne a la decisión de focalizarse en la penetración y en el coito. Si el coito es de hecho la principal causa de todas las brutalidades sexuales, y la base actual de la dominación que ejercen los hombres sobre las mujeres, entonces la única forma de modificar la situación actual debe apuntar hacia el coito mismo. Pero la penetración parece ser indisociable del mismo ¿Eso significa que el coito debe ser prohibido o considerado cuanto menos como una práctica sexual extrema, análoga, por ejemplo, al bondage? Debería prevalecer la procreación sin coito, dado que los nuevos desarrollos de la investigación científica la hicieron posible. La fertilización in vitro podría convertirse en el método preferencial a ser adoptado por las parejas políticamente conscientes. Podría incluso hacerse obligatorio. Además, podría combinarse con un estricto control del nacimiento que algunos ecologistas consideran como algo inevitable, si los problemas del cambio climático deben ser tratados de manera efectiva. A pesar de que tales desarrollos parecen pertenecer en la actualidad a las novelas de ciencia ficción o las series de televisión, no hay ninguna manera fundamentada en los principios para que el movimiento Me Too sexual pueda excluirlos ¿ Es este un ideal político o social aceptable para los seres que, hasta ahora, fueron llamados humanos y que, en un futuro cercano, podrían ser irreconciliablemente divididos en dos subespecies anatómicamente opuestas, una masculina y la otra femenina?

Es bastante inquietante escuchar, en las acusaciones dirigidas contra los hombres tomados como un grupo homogéneo, los ecos de acusaciones análogas que en el pasado fueron, y todavía lo son a veces, dirigidas contra otros grupos "homogéneos", especialmente los denominados salvajes, o los judíos, o los amerindios, o los afroamericanos, o los latinos o los inmigrantes de todos los orígenes. Una vez más, debemos referirnos a Lacan (Lacan, 1995, p. 12, y 2015, p. 16). ${ }^{15}$ Él predijo que el crecimiento del mercado mundial sería seguido por demandas crecientes de segregación. Tal demanda está innegablemente latente en el movimiento Me Too sexual. En otras palabras, se considera a la libertad material de las mujeres como si requiriera un apartheid que segregue a los hombres sexualmente maduros del resto de la sociedad.

El cuarto interrogante concierne a la noción de debilidad estructural. Es imposible para el movimiento Me Too sexual tolerar algunas formulaciones demasiado simplistas que encontramos en los medios masivos y de acuerdo a las cuales las mujeres supuestamente poseen el monopolio de la debilidad. Casi inmediatamente surge una objeción: ¿Qué pasa con la relación entre niños o adolescentes y adultos? ¿Es posible afirmar sin reservas que una mujer adulta es estructuralmente más débil que un niño varón o incluso que un varón adolescente? Sin tomar posición sobre la acusación dirigida por un joven comediante contra la directora de cine Asia Argento, lo importante es tanto el hecho de que haya hecho surgir el problema como el poco tiempo que tardó en hacerlo. Desde un punto de vista más general, debería ser aceptable, incluso para quienes lideran el movimiento sexual $M e T o o$, aceptar que, en las relaciones sexuales en particular y en las relaciones sociales en general, los niños o los adolescentes son la parte más débil en relación con los adultos, incluso cuando se trata de varones frente a una mujer adulta. La pedofilia no está confinada a los límites de la Iglesia Católica, ni a los hombres adultos.

\section{Acerca de un defecto en el programa del Me Too}

La discusión sobre los niños y los adolescentes inmediatamente lleva a la cuestión del ambiente familiar y del incesto. En ese dominio, debería estar claro que la parte estructuralmente más débil no son las mujeres per se.

Por el contrario, al insistir en el estatus de las mujeres adultas y en la penetración, la filosofía del movimiento Me Too sexual se vio llevada a olvidar un fenómeno masivo: los actos de violencia ejercidos sobre mujeres jóvenes antes de que sea dado suponer que hubo algún tipo de penetración. La práctica de la circuncisión femenina es un punto que lo ilustra. No solo se encuentra bastante extendida, sino que sigue creciendo. En nombre del multiculturalismo, muchos países occidentales se rehúsan a tomar cualquier medida en contra de este desarrollo. A pesar de que pueda argumentarse que la práctica deriva de un sistema patriarcal de valores, es a menudo impuesta y realizada sobre las mujeres jóvenes por mujeres adultas (sus madres, tías, abuelas, etc.). En esos casos, la característica relevante no es la dominación de los hombres sobre las mujeres, sino la dominación de los adultos sobre los niños. ${ }^{16}$

Por mucho tiempo, las mujeres protestaron contra el uso del sustantivo hombre para designar la humanidad en general, pero el mismo defecto marca el uso del sustantivo mujer y del adjetivo femenino [feminine] para designar a los seres humanos hembras [female] en gene- 
ral, sin tomar nota del hecho de que las niñas son sometidas a violencias específicas. No hay razón para confundir una niña con una mujer adulta, dado que los riesgos a los que se encuentran expuestas no son en ninguna medida los mismos. El uso demasiado espontáneo de la frase "los derechos de las mujeres" implica la misma negación que el uso de la frase "derechos del hombre". Incluso suscribiría a la hipótesis de que, en la actualidad, tal negación implica consecuencias más peligrosas.

Ciertamente, por el momento, la práctica de la circuncisión femenina sigue siendo una especificidad de culturas a cuya existencia el movimiento $M e$ Too no parece aludir con frecuencia, si es que lo hace alguna vez. Pero, si esto se confirma, tal falta de atención es inexcusable. Si el movimiento y su filosofía sexual no modifican su propensión a negar la desigualdad específica entre niños (o adolescentes) y adultos, si la consideran como una subclase de la relación desigual entre adultos, y si, además, siguen olvidándose de las sociedades que existen afuera de los estrechos círculos que han adoptado el modo de vida liberal capitalista, entonces el desastre es inevitable. El movimiento Me Too sexual emergerá como una nueva versión del sistema de valores protestante blanco y anglosajón. En nombre de la civilización, conllevará el mismo rechazo hacia los denominados salvajes (en otras palabras, hombres en tanto tales, pero también nativos, negros, judíos, latinos, inmigrantes, etc.) y el mismo horror a la realidad física de los cuerpos por cuya presencia insoportable se los acusa.

El movimiento Me Too sexual conlleva la temible posibilidad de una evolución de este tipo. Todavía más en la medida en que su contraparte "profesionalista" ha elegido abiertamente el camino de la ideología protestante, anglosajona y blanca. De acuerdo con su perspectiva, el aspecto principal en el caso de Harvey Weinstein tiene que ver con el hecho de que los asaltos sexuales sucedieron en un marco profesional, entre un hombre que ejercía un poder casi absoluto en la industria del cine y mujeres que querían hacer una carrera en esa industria. Dos problemas surgen entonces: a) es impermisible para cualquier individuo hacer uso de su posición profesional para satisfacer sus fantasías personales (sean sexuales o no); b) mientras que no hay nada malo con el poder casi absoluto que algunos individuos ejercen (suponiendo que sigan siendo profesionales), hay algo fundamentalmente malo en el hecho de que las mujeres no ocupen esa posición.
El aspecto sexual del abuso del poder profesional no es más lo esencial; visto desde el punto de vista de la ética profesional, la gravedad de la ofensa hubiera sido la misma incluso si hubiese involucrado una idiosincrasia no sexual, como el consumo compulsivo de alcohol o jugar a la ruleta de manera forzada. Las regulaciones sexuales son necesarias, por supuesto, pero funcionan como un componente en las regulaciones generales que deben imponerse a la vida profesional y que conciernen al estatus respectivo de hombres y mujeres. Consecuentemente, la principal meta de esta versión específica del movimiento Me Too es doble: por un lado, la vida profesional debe estar gobernada por contratos que específicamente excluyan cualquier comportamiento, por más inocuo que pueda ser, que una mujer pueda experimentar como (sea física o moralmente) ofensivo o coercitivo; por otro lado, la vida profesional debe abolir cualquier regla, por más insignificante que sea, que una mujer pueda experimentar como ventajosa para los hombres.

En esta concepción, el acoso sexual es entendido de una manera en la cual se vuelve uno de los componentes de una noción más general de acoso. Esta noción es en efecto tan amplia como para incluir la mera presencia física de cuerpos masculinos en un espacio que las mujeres puedan experimentar como estrecho.

Según fuentes bien informadas, el enfoque profesional se está volviendo cada vez más extendido en la sociedad estadounidense actual. El enfoque sexual del movimiento $M e$ Too, sin embargo, no ha desaparecido. De hecho, todavía prevalece afuera de EEUU. No es sorprendente entonces que las dos versiones del movimiento se influencien una a la otra. Si la versión "profesionalista" del Me Too llega a afectar a su versión sexual con una profundidad excesiva, entonces todas las limitaciones que señalé se volverán efectivas. En ese caso, las esperanzas despertadas por la primera etapa del $\mathrm{Me}$ Too habrán sido aplastadas. Ciertamente, el número de mujeres poderosas y con altos salarios incrementará. Eso conllevará grandes cambios en la composición de la pequeña élite que gobierna las pocas súper potencias y en sus Estados satélites. Incluso si esa evolución beneficiara a mujeres de las clases medias altas y clases medias bajas, su impacto será simbólicamente importante y materialmente limitado. La situación efectiva de las mujeres alrededor del mundo no cambiará. No hay tal cosa como un efecto de derrame en la economía; tampoco hay nada como un derrame en cuestiones sociales. 


\section{Referencias}

de Beauvoir, S. (2005) El segundo sexo, trad. Alicia Martorell. Prólogo Teresa López Pardina. Madrid: Ed. Cátedra.

de Beauvoir, S. (2010) The second Sex, trans. Contance Borde and Sheila Malovany-Chevallier. New York: Alfred A. Knopf.

Freud, S. (2001 [1912]) “On the Universal Tendency to Debasement in the Sphere of Love”, trans. and ed. James Strachey, The Standard Edition of the Complete Psychological Works of Sigmund Freud XI: 177-90. London: The Hogarth Press and the Institute of Psycho-Analysis.

Freud, S. (1912) "Sobre la más generalizada degradación de la vida amorosa (Contribuciones a la psicología del amor, II) [1912], ed. James Strachey, Obras completas. Volumen 11. Cinco conferencias sobre psicoanálisis, Un recuerdo infantil de Leonardo da Vinci y otras obras, trad. directa del alemán de José L. Etcheverry, pp. 173-185. Buenos Aires: Amorrortu.

Kant, I. (1873) Principios metafísicos del derecho, trad. G. Lizarraga. Madrid: Fondo Antiguo de la Universidad de Sevilla; reproducción fotográfica facsimilar del original Recuperado de: http://fama2.us.es/fde/ocr/2006/principiosMetafisicosKant.pdf

Kant, I. (1887) The philosophy of Law: An Exposition of the Fundamental Principles of Jurisprudence as the Science of Right, trans. William Hastie. Edinburgh: T. \& T. Clark. Recuperado de: https://oll.libertyfund.org/titles/kant-the-philosophy-of-law

Kant, I. (1996) The metaphysics of Morals, trans. and ed. Mary Gregor. Cambridge, UK: Cambridge University Press.

Kant, I. (2008) La metafísica de las costumbres, trad. y notas de Adela Cortina Orts y Jesus Conill Sancho. Madrid: Tecnos.

Lacan, J. (1995) “Proposition of 9 October 1967 on the Psychoanalyst of the School”, Analysis 6, 1-13.

Lacan, J. (2001) “Joyce le Symptôme”, Autres Écrits .París: Éditions du Seuil. 565-70.

Lacan, J. (2012) “Joyce el síntoma”, Otros escritos, trad. Graciela Esperanza y Guy Trobas. Colaboración de Antoni Vicens. Buenos Aires: Paidós. 591-597.

Lacan, J. (2015) “Note sur le père”, La Cause du désir, 1 (89).

Lacan, J. (2015b) “Proposición del 9 de octubre de 1967 sobre el psicoanalista de la Escuela”, Otros escritos, trad. Graciela Esperanza. Revisión de Graciela Esperanza y Guy Trobas. Buenos Aires: Paidós. 261-279.

Lacan, J. (2016) “Nota sobre el padre”. Lacaniana, Año XI (N²1).

Marx, K. (1990) Capital, Vol. 1, trans. Ben Fowkes. New York: Penguin.

Marx, K. (2008) El capital, Tomo I/Vol. I. Libro primero. El proceso de producción del capital, trad. Pedro Scaron. México: Siglo XXI.

Milner, J.C. (2018) “D’une sexualité a l’autre”, Juan Pablo Lucchelli, Jean-Claude Milner, and Slavoj Žižek, Sexualités en travaux, 1568. París: Éditions Michèle.

\footnotetext{
${ }^{1}$ En el caso de los textos citados en el artículo, agregamos la referencia en pie de página a las traducciones disponibles y autorizadas. En los pocos casos en los cuales consideramos que podrían existir matices de interpretación, hemos citado las traducciones en pie de página. En el cuerpo del texto optamos por traducir las citas directamente del inglés. Consideramos que de esta forma se conserva mejor el sentido que el autor busca destacar a lo largo de su argumento principal. Aprovechamos para agradecer a Fabián Fajnwaks por haber hecho llegar esta traducción a J.C. Milner, quien generosamente autorizó su publicación.

${ }^{2}$ Agradezco al profesor Daniel Heller-Roazen por haberme señalado la importancia del enfoque "profesionalista”.

${ }^{3}$ Un estudio más detallado puede encontrarse en Milner, 2018.

${ }^{4}$ La cita se encuentra en un apéndice a la Doctrina del derecho, Observación 3, agregada en 1789 a la segunda edición de la Metafísica de las costumbres; la primera edición había sido publicada en 1796. Debe notarse que la Metafísica de las costumbres está dividida en dos partes, la Doctrina del derecho y la Doctrina de la virtud. [Hay traducción al español de ambos textos. En los Principios metafísicos del derecho, G. Lizarraga traduce la frase como sigue: "Sin esta condición el disfrute carnal es siempre caníbal en principio (aunque no siempre en cuanto al efecto)” (Kant, 1873, p. 237). En La metafísica de las costumbres, Adela Cortina Orts y Jesus Conill Sancho traducen: "Sin esta condición, el goce carnal es siempre, según su principio (aunque no siempre según el efecto), caníbal" (Kant, 2008, p. 202) (N. del T.)]
}

${ }^{5}$ Para la traducción al español, véase Kant, 1873 pp. 111-117 (N. del T.)

${ }^{6}$ Dejo de lado los detalles de la teoría de la plusvalía, a pesar de que adhiero a ella. La noción de plusvalía pertenece al análisis específico del trabajo humano, mientras que mi propósito aquí es considerar sólo las nociones generales de contrato y de uso.

7 Para la traducción al español, véase Kant, 2008, p. 202 (N. del T.)

${ }^{8}$ Los pasajes esenciales se encuentran en los primeros capítulos de El Capital, Vol. 1. Cf. la sección titulada "Los dos factores de la mercancía: valor de uso y valor (sustancia del valor, magnitud del valor)” (Marx, 1990, pp. 125-131). [La traducción al español se encuentra en Marx, 2008, pp. 43-51 (N. del T.)] 
${ }^{9} \mathrm{El}$ juego de palabras se produce porque en inglés el verbo master engloba tanto la noción de dominio como la de saber (N. del T.)

${ }^{10}$ Para la traducción al español, véase de Beauvoir, 2005, p. 371 (N. del T)

${ }^{11}$ El artículo está basado en una conferencia de 1975. [Hay traducción al español en Lacan, 2012 (N. del T.)]

${ }^{12} \mathrm{El}$ pronombre indefinido on deriva históricamente del latín homo. Puede solo referir a seres humanos, sin determinar su cantidad. A pesar de que el número que le corresponde es siempre singular, on puede designar tanto una multiplicidad anónima como un individuo anónimo. [Graciela Esperanza y Guy Trobas traducen: “puesto que el hombre tiene un cuerpo, es por el cuerpo por lo que se lo tiene” (Lacan, 2012, p. 595). (N. del T.)]

${ }^{13}$ Lo mismo vale para el español hombre (N. del T.)

${ }^{14}$ Para la traducción al español, véase Freud, 2003, p. 183 (N. del T.)

${ }^{15}$ La afirmación pertenecía originalmente a una intervención oral que tuvo lugar en 1968 [Hay traducciones al español en Lacan, 2015b, p. 276 y 2016 (N. del T.)]

${ }^{16}$ Estas consideraciones sobre la circuncisión femenina se apoyan en gran medida en un trabajo todavía inédito de Dominique Sigaud. Ella dirige en la actualidad una investigación exhaustiva acerca del estatus de las niñas en varias sociedades. Me concedió el acceso a su documentación y a las conclusiones que alcanzó a partir de ella. Estoy muy agradecido por esta valiosa información. 